\title{
A Non-Profit University And A For-Profit Consulting Company Partner To A Offer A New Master's Degree
}

Gary Whitney, University of San Diego

Thomas M Dalton, University of San Diego

\begin{abstract}
The University of San Diego, School of Business Administration (non-profit university) and the Ken Blanchard Companies (for profit management consulting company) teamed to create the Master of Science in Executive Leadership at USD. Fusing a traditional non-profit university faculty and staff with a for-profit consulting company created a plethora of financial, cultural, and marketing issues. These issues were solved through a creative and collaborative process. Ultimately the new master's degree thrived both financially, and developed into a popular program for upwardly mobile business executives.
\end{abstract}

Keywords: For-profit, non-profit, masters, degree, leadership

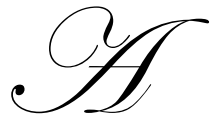

casual golf game between Ken Blanchard (co-author of The One Minute Manager) and a University of San Diego (USD) development officer sparked the creation of an innovative new leadership master's degree at the USD School of Business Administration. Conversations during the golf outing led to further meetings between Ken Blanchard and Business School Dean Curtis Cook to explore the idea of a joint Masters of Science in Executive Leadership (MSEL) degree program that would combine the consulting experience of the Ken Blanchard Companies (KBC) and the academic expertise of USD. Ultimately, faculty and consultants from both entities formed several working committees and developed the degree program.

$\mathrm{KBC}$ is a family-owned firm that provides management and leadership training for many large private and public companies. The company's approach to management and leadership is based on the ideas and theories originally developed by Ken Blanchard and Spencer Johnson in the best selling book The One Minute Manager. The University of San Diego is a non-profit, Catholic university with an AACSB accredited business school. The business school was recently ranked among the top 50 undergraduate business programs in the United States by BusinessWeek.

After initial discussions, Ken Blanchard and Curtis Cook made a commitment to bring together their two organizations for the purpose of creating a master's degree program. KBC staff, most of whom were doctorally qualified, would bring a wealth of consulting and practical business experience to the program - while USD faculty would bring expertise in the traditional academic disciplines of accounting, finance, marketing and statistics. Key administrators from both KBC and USD formed committees to explore whether the MSEL program was feasible specifically, whether the two organizations' cultures, values, and processes were compatible. After several weeks of discussion, the committees agreed to move forward with the project and adopt the following goals:

- $\quad$ Create a cohort-based experience for MSEL students

- Create a community experience within the cohorts which would enable students to build collective norms and values

- $\quad$ Schedule courses into weekend "blocks" for the convenience of out-of-town students

- $\quad$ Focus the program on developing socially responsible leaders. 


\section{ISSUES}

Neither KBC nor USD had developed joint programs of this nature before. Therefore, the program faced several immediate issues:

- Defining the curriculum, including:

- Developing an appropriate balance between traditional college business topics and personality oriented leadership topics

- Differentiating the MSEL from a traditional MBA degree

- $\quad$ Defining the target market, including:

$\circ \quad$ Developing admissions criteria

$\circ \quad$ Creating an effective marketing approach

- $\quad$ Faculty integration, including

$\circ \quad$ Resolving teaching style differences between USD professors and KBC management consultants

$\circ \quad$ Integrating non-traditional leadership and management courses with traditional university business courses

$\circ \quad$ Establishing an on-going dialog between USD professors and $\mathrm{KBC}$ personnel

- $\quad$ Defining the legal structure, including:

- Establishing an entity

$\circ \quad$ Negotiating ownership and control of the program

$\circ \quad$ Creating an acceptable revenue and expense sharing arrangement between KBC and USD

Management from KBC and the USD School of Business formed an Executive Committee and several subcommittees to resolve these issues. The Executive Committee hired a Program Director to implement policies developed by the committees. Together, the committees and program director created innovative solutions for these issues.

\section{CURRICULUM DEVELOPMENT}

A Curriculum Committee comprised of three KBC consultants and three USD professors was formed to develop a curriculum model. A list of the original program courses are presented in Exhibit One. The committee established several design concepts for curriculum:

- $\quad$ The curriculum would be cohort-based. All students would enter and graduate together. There would be no course waivers

- $\quad$ Each course would be three semester units

- $\quad$ Each three-unit course would meet Friday, Saturday, and Sunday for two weekends - except for the first and sixth courses that would meet for a full week in the summer

- $\quad$ There would be two faculty members jointly teaching each course, and both would be in the classroom at all times to keep the pace, variety, and energy high

- The MSEL degree would require 11 courses (33 units) with approximately 15 units devoted to various aspects of leadership and 15 devoted to core business functions - and one three-unit integrative course at the end

\section{MARKETING THE PROGRAM}

\section{Target Market And Admissions}

A Marketing Committee formed to establish a marketing plan for the MSEL Program. The Marketing Committee developed an MSEL student profile. This hypothetical student is a person who is primarily seeking leadership skills, as opposed to technical skills. This approach sought to differentiate the MSEL from the MBA and avoid direct competition with other master's programs such as the MBA. The Marketing Committee envisioned that this student would be an upwardly mobile executive in mid-career with the following characteristics: 
- $\quad$ A supervisor with direct responsibility for leading subordinates

- $\quad$ A working professional with eight or more years of work experience

- $\quad$ A graduate with a bachelor's degree from accredited school (any major)

- A person with a record of leadership within an organization

After four years of MSEL operations, an alumni survey revealed that the actual student typically was an upwardly mobile executive in mid-career. The survey also found:

- $\quad$ Seventy-nine percent had direct responsibility for subordinates

- $\quad$ Twenty-one percent of students were in staff positions or between jobs

- Students had an average of 12 years of management experience before enrolling

- $\quad$ Thirty-five percent of students were employer sponsored, $35 \%$ self-financed, and $26 \%$ were both selffinanced and employer financed

- $\quad$ All students had a record of leadership in an organization

The original application form for MSEL admission was virtually the same as that used for the USD traditional MBA program - including a requirement for GMAT scores, transcripts, a personal essay, and letters of recommendation. Organizers eventually made three important observations:

- $\quad$ Executives did not want to take the standardized GMAT

- $\quad$ Transcripts were likely to be poor indicators of current performance (probably because they represented academic achievement from many years earlier)

- $\quad$ GMAT scores were not good predictors of MSEL performance

In response to these observations, several changes were made. First, MSEL applicants were encouraged to submit a "professional product" in lieu of GMAT scores. This was intended to be a document or project that demonstrated the applicant's ability to analyze complex problems at the graduate level. Examples of products submitted by applicants included technical reports, strategic business plans, financial analyses, and new project or business proposals. Second, letters of recommendation would use the 360 degree concept - that is, a recommendation from a superior, from a subordinate, and from a peer in the organization. (Some flexibility was required in this regard. For example, CEO's of privately held companies typically have no direct superior). Third, more weight was given to achievements after a bachelor's degree as predictors of leadership potential, than to undergraduate activities.

\section{Marketing}

Although the program envisioned students flying to USD from all over the country to attend the program, resources were insufficient for a nation-wide advertising program. The program, therefore, began with newspaper advertising in major cities "within one Southwest Airlines hop" from San Diego. This area includes Phoenix, Las Vegas, Orange County, and the San Francisco bay area. The highest advertising yield came from local ads in the San Diego Union-Tribune. There was enough response from this one source to begin the first cohorts.

By cohort seven, the MSEL program still ran newspaper advertisements in the local San Diego paper but also used email lists, a USD web page, and space on the KBC web pages. The Program Director made sales calls to local executives. The Program Director and an alumni-CEO together made sales calls to company presidents.

These first-contact marketing methods invited potential applicants to come to "informational sessions" held on campus. These sessions included presentations by the MSEL director, a mini-lesson by a faculty member, and a few words from the Dean and Ken Blanchard. Later informational meetings also included one alumnus seated at each table during the meetings to guide discussion and answer questions. Alumni turned out to be powerful sales tools, prompting some potential students to come to multiple informational sessions before applying. 
Follow-up by the MSEL Program Director became a major driver in converting an inquiry into an application. Applicants expect and demand a high degree of personal attention from the beginning of the process through graduation. Fortunately, the first Program Director had relevant academic credentials and strong interpersonal skills. Recruiting executive leaders for an expensive program required personal attention and consistent follow-up.

\section{FACULTY INTEGRATION}

The $\mathrm{KBC}$ culture of consulting is driven by a concern for billable engagements and frequent travel, whereas the USD culture is driven by teaching schedules and research demands. Links were necessary to overcome these differences and avoid derailment of efforts to form a coherent educational program. Faculty from both KBC and USD met frequently to communicate and resolve issues. Meetings were generally full or half-day sessions requiring faculty to explain and demonstrate teaching techniques to other faculty. Further, KBC invited USD faculty to attend proprietary teaching improvement courses instructed by KBC consultants.

The Executive Committee initiated a review of student evaluation forms from each course immediately after each class. Although most faculty members received high praise from students, some issues arose and required Executive Committee attention. Issues included:

- $\quad$ Slow or no feedback from faculty on term papers

- $\quad$ Semester grades given by faculty with no explanation

- $\quad$ Faculty giving blanket " $A$ " grades to all students

- $\quad$ Student resistance to any grading (usually from executives accustomed to being in charge)

- $\quad$ Class absences because of student work conflicts

Hiring a full-time Program Director addressed some of these problems. The Program Director now serves as the primary recruiter and focal point for communications between the Executive Committee, faculty, and students. The Executive Committee and Program Director now review all admissions.

\section{LEGAL STRUCTURE}

There are two primary approaches to organizing joint ventures between non-profit educational institutions and for-profit entities. The venture can be co-owned or the venture can be owned entirely by one organization, which then hires services from the other organization.

\section{Co-Ownership}

The MSEL program was originally envisioned as an equal partnership between USD and KBC. Each organization was expected to contribute equally to the financial resources and instructor talent. In return, each organization was expected to share management responsibility and net profits.

A corporate form of co-ownership was briefly considered but abandoned. Although there are no absolute legal barriers that prevented USD and KBC from forming a jointly owned corporation, corporations are cumbersome and do not allow the same flexibility as unincorporated entities such as partnerships. A partnership is not a separate legal entity from the owners, and therefore allows more direct control by the owners. Further, unless a corporation has been granted its own tax-exempt status, all profits from the venture are subject to income tax. S-corporation status is unavailable because S-corporation rules require that the co-owners be individuals, not corporations. $\mathrm{KBC}$ is a for-profit corporation and USD is a 501(c)(3) non-profit corporation.

Through consultation with an attorney, organizers determined that a limited liability type of partnership is generally the preferred form of co-ownership between a non-profit educational institution and a for-profit entity. A limited liability company (LLC) is a type of partnership that provides limited liability for all partners (including 
those who would normally be considered "general partners"). For these reasons, USD and KBC originally decided to form an LLC as the organizational shell for the MSEL program.

\section{LLC Issues}

Although flexible, LLCs between non-profit entities and for-profit entities present special problems. The primary concern is protecting the tax-exempt status of the non-profit partner. To remain tax-exempt, an entity must be organized and operated exclusively for its tax-exempt purpose. A non-profit organization that becomes partners with a for-profit company in a money-making venture can easily stray from this mandate. The IRS is keenly aware of this possibility and examines non-profit and for-profit partnerships with a harsh lens.

Fortunately, several court cases and Internal Revenue Service rulings have provided guidance in forming non-profit and for-profit partnerships - LLCs in particular - so that the tax-exempt status of the non-profit partner is protected. Although there are no safe harbor rules that guarantee protection of tax-exempt status, several recommendations exist that, if followed, can reasonably protect the non-profit entity. In general, these recommendations are meant to ensure that the LLC is formed and operated exclusively to further the tax-exempt purpose of the non-profit partner. These recommendations are listed in Exhibit Two.

\section{Single Ownership}

Originally, USD and the KBC created an operating agreement for an LLC as the organizational structure for the MSEL program. This operating agreement complied with each of the recommendations listed in Exhibit Two.

However, USD administration found the LLC approach to be unduly complicated. LLC agreements can be immense documents, written in confusing legalese with cryptic references to Internal Revenue Code sections. Consequently, the LLC approach was abandoned and the School of Business Administration was ordered to find a simpler way.

When a non-profit entity owns the entire venture, LLC complexity is eliminated. Further, there is little risk of jeopardizing tax-exempt status because the non-profit entity has complete legal control over the program. USD administration eventually decided against operating the MSEL program as co-owners for these reasons. The MSEL organizers then redirected their efforts toward a single owner structure.

Single ownership, although simpler, introduces its own set of issues. In the case of the MSEL program, the intent was to combine the best features of USD and KBC by fusing both organizations as equal participants. Without an equal ownership interest, this whole concept was in danger. At least three specific issues emerged.

First, would KBC participants feel a sense of ownership in the program? Fortunately, the original participants from $\mathrm{KBC}$ came with an intense sense of purpose. The form of ownership seemed to matter little as they assumed an assertive role in program design from the beginning. In fact, the program had been organized and operating for over a year before any legal document had been signed by either party. The final legal contract, when completed, simply formalized a process that had evolved between USD and KBC.

By the time the organization issue was resolved, university and $\mathrm{KBC}$ employees had developed a culture of equal control and participation. Each of the Executive Board members (whether from USD or KBC) had an equal vote on major decisions from the beginning. All faculty members, whether from USD or KBC, were expected to participate and contribute to curriculum development and program structure.

Legally, all instructors from KBC are university employees (adjunct professors) while teaching MSEL courses. This relationship fosters a sense of belonging to the university while retaining university control. Executive Board members from KBC teach MSEL courses as adjunct faculty members, further strengthening KBC ties to the program and to USD. 
As a program entirely owned by USD (as opposed to a co-owned partnership), all participants (including the MSEL Executive Board) ultimately report to the School of Business Dean. This command structure keeps ultimate control of the program within USD as required by accreditation rules. It did not; however, appear to diminish KBC's commitment to the MSEL program.

The second issue was how to compensate KBC with a share of profits as originally intended. As an LLC, KBC would have received one-half of the net profits. As development efforts moved to a single owner approach, $\mathrm{KBC}$ was in danger of losing the full amount of its envisioned revenue. The other side of this issue is risk. As a single owner, USD would now be assuming the entire risk of failure. Both sides of this issue required attention. The answer came in the form of a sliding royalty schedule to KBC loosely based on expected profits.

USD and KBC agreed on a royalty payment schedule that provides higher royalties per student to KBC for large cohorts and smaller royalties per student for small cohorts. This sliding scale allows USD more resources to cover fixed costs when cohorts are small, and provides $\mathrm{KBC}$ a royalty approximately equal to half of the profits when cohorts are average sized or large.

The royalty schedule was calculated after reviewing revenue and expense projections for the program. Because USD has experience in costing educational programs held on campus, the estimates were reasonably accurate and helped define a royalty schedule that would compensate $\mathrm{KBC}$ at about the level originally intended.

The third issue was how $\mathrm{KBC}$ could retain reasonable management influence over the MSEL program as a non-owner. This issue was solved by carefully detailing KBC's rights and responsibilities under the royalty agreement. KBC has the right and responsibility to provide three of the seven board members. USD also provides three board members. Pursuant to MSEL alumni requests, an MSEL alum was added as the seventh board member. One student from each of the active cohorts also attends the public portion of the board meetings. KBC also has the right and responsibility to provide approximately half of the instructors.

KBC has the right and responsibility to provide occasional space for MSEL activities. Some MSEL classes were originally scheduled at KBC headquarters. However, student feedback indicated that students would rather attend classes at the university campus. MSEL Executive Board meetings and retreats alternate between USD and $\mathrm{KBC}$ headquarters.

\section{Financing}

The Executive Committee drafted an initial budget based on approximately $\$ 40,000$ tuition for the entire degree. This tuition fee included books, parking, food, supplies, plus access to campus facilities. The intent of a "one price" degree was to avoid any financial surprises for the students and to maximize the value of time on campus by avoiding trips to the bookstore and parking services. Because the program expected employers to sponsor most students, a "one price" approach would minimize out-of-pocket expense for most individual students.

The first year budget break-even point was approximately 13 students. To keep the integrity and strength of a powerful cohort experience, the program set an upper limit of 30 students. USD and KBC provided seed money to meeting initial expenses but it was essential that the new degree show positive cash flow in the first year of operations. This required a strong marketing effort.

USD kept the program "off-budget." The revenue was not included in USD's budget plan and teaching was not a part of the faculty's regular teaching load. Faculty, both KBC and USD, were paid for the courses taught from the MSEL program funds. The MSEL program has produced a surplus every year since inception (after expenses including the $\mathrm{KBC}$ royalty payment). 


\section{CONCLUSIONS}

Development of this program yielded several important observations that can aid in creating innovative master's degrees.

\section{Curriculum And The Cohort Experience}

- $\quad$ The balance between functional business courses and leadership courses can be sufficiently differentiated from the MBA so that a program attracts new students without cannibalizing from an existing MBA program

- $\quad$ Student cohorts can become cohesive, contributing substantially to learning

- Anything that weakens the cohort, such as allowing late admissions, leaves-of-absence, and similar disruptions weaken the student experience.

- $\quad$ Structuring "community time" effectively into a cohort can resolve interpersonal and group issues

- With some cohorts, a facilitator supplied by the program will enhance the cohort experience

- $\quad$ Professors are challenged to create new and innovative teaching methods when partnering with experienced business consultants

- $\quad$ Professors will transfer teaching methods developed in an innovative program to more traditional programs

- $\quad$ The cohort experience can enhance degree completion rates (MSEL completion rates have been above 90 percent)

- $\quad$ Alumni surveys are an important tool in refining a graduate program

\section{Ownership, Control, And Administration}

- $\quad$ Single ownership by the non-profit entity eliminates unnecessary complexity and preserves the rights and responsibilities of both parties

- Keeping a program separate from the university's regular budget allows flexibility to respond to program needs

- A Program Director is essential as the single point of contact for students and as an interface with the university administration

- An off-budget program can create an enduring, substantial revenue stream for the school and university

- An off-budget program can generate additional income for professors, helping to boost salaries for the most productive instructors

\section{Marketing}

- $\quad$ Traditional university marketing efforts (i.e., admissions) are not oriented to attracting executives

- The succession from advertisement, to informational session, to the application, to personal contact with the director, is a very effective recruiting process.

\section{Summary}

Creation of the MSEL program at USD was very beneficial to the School of Business. As a pilot program, it paved the way for other innovative master's degrees such as the Master of Science in Global Leadership, the Master of Science in Supply Chain Management, the Master of Science in Information Technology, the Master of Science in Real Estate, and the Master of Science in Accountancy. Without the lessons learned from the MSEL, these subsequent programs would have been more costly and less effective. The MSEL program illustrates that innovative partnerships can be successfully developed between non-profit universities and for-profit businesses. Although many issues must be addressed, the pay-off can be substantial. 


\section{EXHIBIT ONE}

\section{MSEL Curriculum 2005}

MSEL 501 Preparing for Leadership: Self-Appraisal and Analysis (3)

MSEL 502 Optimizing Individual Learning (1.5)

MSEL 503 Organizational Ethics I (1.5)

MSEL 504 Data Analysis \& Decision Making (3)

MSEL 505 Communicating your Leadership Point-of-View (1.5)

MSEL 506 Understanding Customers and Markets (3)

MSEL 507 Partnering for Performance Using Situational Leadership II (1.5)

MSEL 508 Accounting for Decision Making \& Control (3.0)

MSEL 509 Leading High Performing Teams (3.0)

MSEL 510 Financial Management and Investments (3.0)

MSEL 511 Leadership in a Global Context (1.5)

MSEL 512 Organizational Ethics II (1.5)

MSEL 513 Sustaining Competitive Advantage: The Learning Organization (1.5)

MSEL 514 Leading Change (3.0)

MSEL 515 Planning and Implementing Organizational Strategies (3.0)

MSEL 516 Leading High Performing Organizations (1.5)

\section{EXHIBIT TWO}

\section{Recommendations For Non-Profit And For-Profit Partnerships}

1. The majority of the LLC governing board should be appointed by the non-profit entity to ensure that the LLC will always be operated exclusively for the tax-exempt purpose.

2. The non-profit governing board members should be required to approve all major decisions relating to the LLC operations.

3. The LLC governing documents should specify the duty of all board members to make decisions for the LLC so as to further its tax-exempt purpose, and that this duty must override any duty to operate the LLC for financial benefit.

4. The LLC governing documents should require that the LLC actually operate in a manner that furthers its tax-exempt purpose.

5. None of the officers, directors, or key employees of the non-profit partner involved in forming the LLC can be promised employment or any other inducement from the LLC or for-profit partner during the formation.

\section{AUTHOR INFORMATION}

Dr. Gary Whitney is a Professor of Management at the University of San Diego. Current activities include working with the Executive Program for Scientists and Engineers (EPSE) at the University of California at San Diego and the Master of Science in Executive Leadership jointly offered by USD and the Ken Blanchard Companies. He is a staff member at the Institute for Quality and Productivity in San Diego. He consults and leads seminars on Total Quality, Team Facilitation, Strategic Negotiation, Decision Making, and Team Building. Past clients include Coca-Cola, Pacific Bell, and Bumble Bee Seafood.

Dr. Thomas M Dalton is a Professor of Accounting and Taxation at the University of San Diego. He has published numerous tax planning articles in professional journals and tax related research studies in academic journals. He is a Certified Public Accountant and teaches courses in financial statement analysis, individual tax, corporate tax, partnership tax, and retirement planning. 


\section{REFERENCES}

1. Dalton, T.M (2005). Structuring joint ventures between for-profit and tax-exempt entities. Business Entities (Vol. 7, No. 1 January/February): 32-37.

2. $\quad$ Section 501(c)(3), Internal Revenue Code of 1986 as Amended.

3. Blanchard, K., Johnson, S. (1982). The One Minute Manager. La Jolla, CA: Morrow.

4. Top Undergraduate Business Programs BusinessWeek, Retrieved May 2008 from http://bwnt.businessweek.com/interactive_reports/undergrad_bschool/

\section{NOTES}


NOTES 